Una selección de textos de:

M A R C O S G H E I L E R

\title{
La educación desde el psicoanálisis
}

La función analítica del educador

Odette Vélez (Compiladora)

$$
\text { (v) UPC }
$$




$$
\begin{aligned}
& \text { Una selección de textos de: } \\
& \text { A R C O S G H E I L E R }
\end{aligned}
$$

La educación desde el psicoanálisis

La función analítica del educador

Odette Vélez (Compiladora)

Lima, junio de 2011 
(c) Universidad Peruana de Ciencias Aplicadas (UPC)

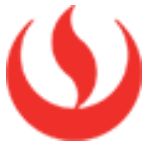

Primera publicación: junio de 2011

Impreso en el Perú - Printed in Peru

Corrección de estilo:

Christian Estrada

Diseño de cubierta:

Germán Ruiz Ch.

Diagramación:

Diana Patrón

Editor del proyecto editorial

Universidad Peruana de Ciencias Aplicadas S. A. C.

Av. Alonso de Molina 1611, Lima 33, Perú.

Teléf. 313-3333

www.upc.edu.pe

Primera edición: junio de 2011

Digitalizado y Distribuido por YoPublico S.A.C.

\section{3 yopublico}

www.yopublico.net

Telf: 51-1-221 9998

Dirección: Av. 2 de Mayo 534 Of. 304,

Miraflores Lima-Perú

\section{Universidad Peruana de Ciencias Aplicadas (UPC) Centro de Información}

Vélez, Odette (compiladora). La educación desde el psicoanálisis. La función analítica del educador

Lima: Universidad Peruana de Ciencias Aplicadas (UPC), 2015

ISBN de la versión impresa: 978-612-4041-76-1

ISBN de la versión PDF: 978-612-4041-90-7

ISBN de la versión e-Pub: 978-612-4191-88-6

EDUCACIÓN, PSICOANÁLISIS, RELACIONES MAESTRO ESTUDIANTE, PSICOLOGIA DE LA EDUCACIÓN

370.15 GHEI

Todos los derechos reservados. Esta publicación no puede ser reproducida, ni en todo ni en parte, ni registrada en o transmitida por un sistema de recuperación de información, en ninguna forma ni por ningún medio, sea mecánico, fotoquímico, electrónico, magnético, electroóptico, por fotocopia o cualquier otro, sin el permiso previo, por escrito, de la editorial.

El contenido de este libro es responsabilidad del autor y no refleja necesariamente la opinión de los editores. 
Los árboles hablan por todas partes. Por las hojas, por las ramas, por las raíces. ¿Quieres ver? Apoya tu oído aquí en mi tronco y vas a escuchar palpitar mi corazón.

José Mauro de Vasconcelos

¿Por qué no vuelves en un sueño para peinarme y bailar un rato?

Alejandra Mitrani

Marcos

canta tu corazón por la raíz, las ramas y las hojas de este nuevo árbol ardiente bosque de ilusiones

¿Por qué no vuelves en un sueño para conversar y reírnos un rato? 


\section{Contenido}

$\begin{array}{ll}\text { Agradecimientos } & 9\end{array}$

$\begin{array}{ll}\text { Introducción } & 11\end{array}$

$\begin{array}{ll}\text { El sembrador } & 23\end{array}$

$\begin{array}{ll}\text { Una experiencia en educación y psicoanálisis } & 27\end{array}$

Acerca del acto educativo y la función analítica del educador 33

La calidad de una educación total $\quad 43$

Del encuentro al vínculo en la relación profesor-alumno 61

La identidad del educador: ¿incógnita de la función pedagógica? $\quad 79$

$\begin{array}{ll}\text { Disciplina } & 89\end{array}$

$\begin{array}{ll}\text { Violencia intraescolar } & 95\end{array}$

¡Dónde está el maestro! 105

Desarrollo humano y creatividad en educación 111

Desarrollo humano, orientación educativa y normas de convivencia 123

y disciplina. Acerca del orden, el caos y la tolerancia

$\begin{array}{ll}\text { La función analítica del educador } & 137\end{array}$

Freud: de la antipedagogía a la reeducación... del psicoanálisis 143

Vínculo profesor-alumno. Un desafío cotidiano 153

Una discusión de las objeciones a la construcción de una pedagogía $\quad 175$ psicoanalítica 


\section{Agradecimientos}

A Marcos Gheiler, por la fortuna de habernos encontrado y de haber cultivado un profundo vínculo de amistad; por haber trabajado juntos y haber aprendido uno del otro; y, sobre todo, por confiarme la responsabilidad de editar y publicar sus conferencias.

A Fanie Malamud, por su infinita paciencia y cariño, y por la gran confianza.

Al Fondo Editorial de la UPC, especialmente a Mónica Jacobs, Úrsula Freundt-Thurne y Milagros Morgan, por creer, desde el inicio, en este proyecto editorial.

A Lili Galván, por su apoyo y entusiasmo para hacer realidad esta publicación.

A Pilar Sousa, por su generoso aporte en la aclaración de ciertos términos psicoanalíticos.

A Christian Estrada, por ser —una vez más- compañero de viaje desde su impecable labor como corrector de estilo.

A Martín, por su atenta y amorosa compañía. 


\section{Introducción}

La obra que hoy tenemos entre manos es una ofrenda para honrar la vida - y también la muerte- de Marcos Gheiler Mucinik, un hombre excepcional, de espíritu intenso y apasionado, de energía vital e impetuosa, comprometido con el logro de una sociedad mentalmente más sana. Este libro es un homenaje para un auténtico pionero que, con entusiasmo inusual, realizó, en el Perú y en otros países de América Latina, una de las más arduas labores académicas y sociales: la aplicación del psicoanálisis a la educación.

Como acostumbraba decirnos, uno de sus principales deseos era acabar con la idea de que un acto analítico solo puede ocurrir en un consultorio. Marcos aspiraba a que el acto analítico también tuviera lugar en el aula y a que los educadores pudieran desarrollar una capacidad analítica de entendimiento del mundo psíquico de sus alumnos. Trabajó con perseverancia para que se les brindara a los maestros una formación en la que pudieran conocerse más a sí mismos y, desde allí, aprender a ser más tolerantes con sus alumnos, sin dejar por ello de ser exigentes. Otro de sus grandes sueños era que la idea de Freud sobre la figura de un educador analizante fuera profundamente estudiada y difundida por otros psicoanalistas, para contribuir con la educación desde el psicoanálisis ${ }^{1}$. En pocas palabras, se propuso el difícil desafío de ofrecerles a las nuevas generaciones - a través del desarrollo de una actitud analítica en maestros y maestras - la oportunidad de educarse para ser mentalmente sanas.

1 Algunos de estos sueños fueron expresados públicamente por Marcos Gheiler en la Revista Ideele (No. 161, marzo de 2004). 
Muchos de sus anhelos se fueron cristalizando gracias a la incansable labor que desplegó durante más de cuarenta años como psiquiatra y psicoanalista, y, en los últimos treinta, como especialista en la aplicación del psicoanálisis a la educación, tarea que difundió, a través de conferencias, ponencias y publicaciones, en diversos eventos nacionales e internacionales, y que lo llevó a ocupar diferentes cargos en el ámbito educativo.

Marcos fue consultor y asesor en varios colegios e instituciones de nuestro país y de Latinoamérica. Asimismo, fue fundador, director y docente del Centro de Desarrollo Humano y Creatividad (CDC), asociación civil dedicada a la formación y especialización en Tutoría y Consejería Educativa; y de la Escuela de Psicoterapia Clínica y Aplicada (EPCA), entidad orientada a formar profesionales psicoanalíticos para trabajar en el consultorio y «más allá del consultorio». Además, desempeñó diversos cargos en diferentes entidades psicoanalíticas, tanto a nivel nacional como internacional.

Testigo y partícipe de importantes transformaciones en maestros y maestras, algunos de sus esfuerzos y logros fueron, con justa razón, gratamente reconocidos. Integró la Comisión para un Acuerdo Nacional por la Educación y, en 2001, sus propuestas fueron incorporadas en los decretos de ley sobre Tutoría y Prevención Integral. Además, recibió del Ministerio de Educación los Laureles Magisteriales en 2002 y las Palmas Magisteriales en 2004.

$\mathrm{Su}$ compromiso con el desarrollo humano lo llevó no solo a profundizar su trabajo clínico con los pacientes, sino también a interesarse por la sociedad y a proyectar su labor hacia esta, empleando las herramientas del psicoanálisis para ayudar a esbozar posibles soluciones a algunos de los principales problemas de la educación y del medio ambiente. Como buen psicoanalista, creía firmemente que para entender qué impulsa a las personas a sentir, pensar y actuar de determinada manera había que comprender los procesos inconscientes de la mente. Marcos definía el inconsciente como «aquella parte no visible del iceberg que es la base y la mayor parte de nuestro ser, que gobierna nuestras vidas más de lo que quisiéramos aceptar, que nos hace ver el rol de los instintos y del deseo». 
En este sentido, estaba convencido de que una sociedad que subestima la importancia del inconsciente, que se resiste a su estudio y que elude su responsabilidad sobre los contenidos del mismo se expone a quedar presa de este, repitiendo errores y dilatándolos eternamente. De allí que su trabajo estuviera orientado a difundir la importancia de aprender a observar y a entender los mecanismos inconscientes - personales y colectivos- que revelan muchos aspectos de nosotros mismos y ofrecen nuevas posibilidades para un mejor entendimiento de nuestra vida.

Maestro en el conocimiento de las complejidades y las paradojas de la mente humana, en el saber de la música, la educación, las plantas y el mundo, sabio en la expresión de su alegría de vivir y aprender, siempre supo cautivarnos con su palabra lúcida y franca. Escucharlo era una invitación a despertar la propia imaginación. Desde que lo conocí -quince años atrás-, el huracán de energía de este hombre traspasó por completo mis inquietudes intelectuales. Era el verano de 1996 y yo me encontraba sumergida en innumerables reflexiones, dudas, ilusiones y decepciones en relación con mis primeros ejercicios como docente. Como le ocurre a la mayoría de profesores jóvenes, por un lado, estaba deslumbrada y entusiasta con todo lo que suponía enseñar (preparar clases, diseñar metodologías, crear evaluaciones, dialogar con los estudiantes); deseaba aplicar en esta tarea mucho de lo que había aprendido en mi formación como psicóloga educacional. Sin embargo, también me sentía confrontada y, por momentos, abrumada con una serie de aspectos interpersonales que surgían en el aula - vinculados con los estudiantes y con la relación que establecía con ellosque sobrepasaban mi comprensión y mi forma de abordarlos, afectaban las condiciones de aprendizaje, y para los cuales ninguna teoría me había preparado suficientemente.

Es así como llegué, gracias a la sugerencia de un amigo, al Primer Curso Interdisciplinario de Capacitación para Educadores y Profesionales Afines, organizado por el Centro de Desarrollo Humano y Creatividad, institución que Marcos dirigía, en el colegio León Pinelo. Fueron cinco meses 
inolvidables. A decir verdad, no tanto por el desarrollo de las motivadoras conferencias que diversos expositores realizaron sobre diferentes temas ni por las interesantes discusiones de textos que tuvimos en diálogo con varios profesionales, sino principalmente, y de manera significativa y singular, por la experiencia vivida en la Discusión Analítica de Casos (DAC), conducida personalmente y de manera brillante por Marcos.

Se trataba de un método de trabajo grupal que él mismo había creado en 1983 para la capacitación de profesionales del campo educativo y que, sin lugar a dudas, condensaba magistralmente la esencia de su propuesta. Era una práctica que permitía que cada uno de los participantes - educadores y otros profesionales afines- comprendiese aquellas cuestiones problemáticas para las cuales nunca teníamos respuestas claras y funcionales, y frente a las cuales siempre intentábamos las mismas soluciones y cometíamos los mismos errores. Se realizaba a partir de casos —situaciones problemáticas - traídos por los propios participantes, lo cual garantizaba que las preocupaciones y las dudas que se suscitaban promovieran un aprendizaje significativo entre nosotros. El relato del caso constituía un estímulo que generaba una suerte de fenómeno grupal. Con frecuencia, el problema era resignificado por el grupo - a modo de caja de resonancia-, lo que permitía descubrir lo primordial en él. La técnica utilizada por Marcos permitía enfocar claramente el obstáculo y nos ayudaba a resolver dificultades de una manera creativa. Así, este trabajo de discusión se convertía en un espacio de intercambio - y no de escucha pasiva - para que reflexionáramos sobre nuestro trabajo, es decir, para que pensáramos en nuestros alumnos, en nosotros mismos como docentes, y, sobre todo, en el vínculo construido entre nosotros y los estudiantes. Siempre nos recordaba que no había forma de entender a un ser humano si no era en su vínculo con los demás.

Estar allí, en ese espacio que rápidamente y de modo familiar empezamos a llamar «DAC», era como ingresar a un lugar especial, casi mágico, donde algo importante siempre emergía, «nos» ocurría. Vivíamos 
una experiencia grupal que favorecía un aprendizaje individual. Traer un caso propio para ser discutido en grupo era un modo no consciente de recordar, a través de esa acción concreta, algo que estaba atrapado en nuestra memoria; era como acercarse inconscientemente a la comprensión de algo no entendido sobre la conducta de algún alumno y la de uno mismo. Así, el escenario de esta metodología nos invitaba - y en ocasiones nos exigía - a comprender nuestra particular manera de reaccionar al modo de ser de nuestros alumnos y a sus particulares comportamientos; a reconocer los mecanismos psicológicos de defensa que solíamos usar para protegernos, y para evitar el dolor y la frustración en determinadas circunstancias; y a conocer nuestras expectativas, nuestras reacciones a la satisfacción o frustración de estas para, desde allí, intentar mejorar nuestro vínculo con los estudiantes.

El arte y la destreza con que Marcos conducía este espacio ayudaban a desentrampar los «puntos ciegos» que usualmente impedían tanto la comprensión del problema como la aplicación de soluciones. La labor continua con este método facilitaba el abordaje de situaciones interferidas por afectos, conflictos internos o emociones que permanecían inconscientes, rescatando las enseñanzas ocultas allí donde solo parecía haber un mero inconveniente de disciplina o alguna disfuncionalidad individual o grupal. De esta manera, se creaba una atmósfera de exploración personal sobre temas particulares que incidían, favorable o desfavorablemente, en la relación con los alumnos. Se generaba una gran oportunidad para atesorar aprendizajes realmente enriquecedores a partir de situaciones cotidianas que examinábamos considerando factores emocionales dejados usualmente de lado.

La Discusión Analítica de Casos nos confrontaba con situaciones nuevas, siempre desde un clima de acogimiento y facilitación. Lo impredecible, lo desconocido y lo insospechado eran su principal compás. Un permanente diálogo entre lo esencial y lo circunstancial permitía asegurar la autenticidad. A partir de la presentación del caso, todos los profesores - y no solamente quienes lo presentábamos - teníamos la oportunidad de contactarnos con características personales que nos llevaban a sentir, pensar y actuar de 
determinadas maneras, beneficiosas o perjudiciales para el estudiante y para el grupo; así, íbamos percibiendo no solo otras alternativas de acción, sino entendiendo y, poco a poco, transformando nuestra lógica habitual ante diversas situaciones - similares o distintas a las planteadas-. Con las transformaciones que se iban operando en el grupo surgían, a su vez, otras nuevas maneras de ser y estar.

Semana a semana, mes a mes - siempre en el contexto de este Primer Curso Interdisciplinario de Capacitación para Educadores y Profesionales Afines-, asistimos con sumo interés a este espacio de DAC. Nos fuimos transformando, fueron cambiando nuestros vínculos en el grupo y, con todo ello, se fueron modificando nuestras acciones pedagógicas en beneficio de nuestros estudiantes. Fue un proceso largo. Y, al experimentar las propias dificultades para alcanzar respuestas profesionales más adecuadas y comprobar que las verdaderas transformaciones personales tomaban tiempo, empezamos a hacernos más capaces de comprender que eso mismo ocurría con nuestros alumnos y, desde ese entendimiento, empezamos a hacernos más capaces de acompañarlos en los procesos de cambio que esperábamos de ellos.

Fue así como conocí a Marcos, en el contexto de la experiencia directa de la Discusión Analítica de Casos, en un lugar privilegiado de aprendizaje y desarrollo personal y profesional que no quise dejar y que, luego, tuve la ocasión de cultivar por un buen tiempo bajo su conducción en otros grupos de DAC. Algunos años después, en 1999, fascinada por su propuesta de trabajo y por su manejo profesional, le propuse formar un grupo de DAC para profesores de la Universidad Peruana de Ciencias Aplicadas (UPC) — donde me desempeñaba como coordinadora de un curso del Área de Humanidades-, experiencia que nos dejó valiosos aprendizajes. Además, ese mismo año tuvimos la oportunidad de coincidir laboralmente en el Plan Piloto de Tutoría en el marco del Proyecto de Bachillerato del Ministerio de Educación, en el cual Marcos ocupó el cargo de consultor y donde también nos ofreció inolvidables lecciones. 
Todas estas experiencias consolidaron un vínculo de mucha afinidad y cariño entre ambos, y fueron la antesala del trabajo que luego realizamos, en 2003, cuando me invitó a enseñar junto con él el curso Psicoanálisis y Educación en la Maestría en Temas Psicoanalíticos de la Pontificia Universidad Católica del Perú (PUCP). Fueron meses de intensa labor de sistematización de reflexiones teóricas que Marcos venía desarrollando hacía años a partir de la lectura de la obra de Freud y otros autores, y de su experiencia profesional. Fue un laboratorio pedagógico, en diálogo permanente con los estudiantes, en torno a la revisión y el análisis de las principales contribuciones del psicoanálisis a la educación, así como a la discusión acerca de la viabilidad de una pedagogía psicoanalítica y de las objeciones a esta.

Y fue recién al finalizar esta tarea que Marcos nos convocó a César Bedoya - sociólogo y amigo-y a mí para colaborar con él en un proyecto que, sin saberlo, se convertiría nueve años después en la presente publicación. Se trataba de un proyecto editorial personal cuyo objetivo era compilar una selección de sus mejores conferencias. César y yo tuvimos la misión de leer sesenta conferencias con el firme propósito de escoger las más destacadas, tomando en cuenta nuestro conocimiento de su trabajo y nuestro criterio profesional. Fruto de esta faena, elegimos inicialmente quince conferencias y sugerimos una serie de ideas para que Marcos emprendiera la publicación de su libro. Desafortunadamente, el tiempo se fue pasando y, como suele ocurrir en muchas ocasiones, el proyecto del libro se quedó en el tintero, opacado por la vorágine laboral y por los nuevos proyectos y prioridades profesionales de su autor.

Sin embargo, años después, en diciembre de 2009, cuando fui a visitar a Marcos al enterarme de la intempestiva aparición de su enfermedad, volvimos a recordar el proyecto y hablamos de él con cierta nostalgia pero también con ilusión. Pude advertir que los ojos le brillaban al pensar en la posibilidad de retomarlo y concretarlo: «Me encantaría sacar adelante el libro y ojalá la vida me alcance para verlo publicado», me dijo aquella vez, razón por la cual 
decidí ayudarlo a hacer realidad ese viejo deseo. Lamentablemente, el tiempo no nos alcanzó para que él pudiera ver esta obra acabada, pero nos queda el consuelo de saber que se fue con la certeza de que este libro se publicaría de todas maneras. La última vez que hablamos, antes de su partida, me dijo: «Te quedas a cargo de esta tarea, pero esta vez tendrás que terminarla tú sola».

Ahora que la obra tiene vida propia, podemos decir «misión cumplida». Esta publicación es un conjunto de catorce conferencias ${ }^{2}$ que Marcos realizó entre 1993 y 2003. Nueve de ellas fueron desarrolladas en nuestro país, en la ciudad de Lima; y las otras cinco, en tres países latinoamericanos - una en Argentina, dos en Brasil y otras dos en Chile-. Estas exposiciones se llevaron a cabo en diversos eventos (congresos de educación, psicología, psicoterapia, psicopedagogía, psiquiatría y psicoanálisis, y jornadas de trabajo en colegios) organizados por instituciones nacionales e internacionales, cuyo objetivo central y común era generar espacios de reflexión sobre la educación, y sobre la relación de esta con otros campos y disciplinas afines. El público al que estas conferencias fueron dirigidas estuvo conformado, principalmente, por profesionales del campo educativo (educadores, psicólogos, directores, tutores, coordinadores y asesores), y por psicoterapeutas, psicopedagogos, psicoanalistas y otros profesionales interesados en la educación.

Esta recopilación de conferencias busca compartir las ideas y las experiencias que Marcos desarrolló a partir de, como señalamos líneas antes, una de sus primordiales pasiones: la aplicación del psicoanálisis a la educación. La reflexión y el diálogo que nos propone en sus exposiciones pretenden, de manera clara y sencilla, presentar muchas de las contribuciones del psicoanálisis a la educación: la existencia del inconsciente y de la sexualidad infantil, así como la necesidad de conocerlos y entenderlos; la importancia de los primeros años en la vida de un ser humano; la relevancia y pertinencia de algunos conceptos — transferencia, contratransferencia, contenido de dos de ellas era muy similar. 
pulsión, proyección, resistencia- y su posible uso en el trabajo educativo en el aula; la idea freudiana de un educador analizante y de una posible pedagogía psicoanalítica; entre otros aportes.

A través de ejemplos y casos breves, estas conferencias proponen pensar la educación como una ética que se vale de recursos de la pedagogía y del arte del psicoanálisis. De manera especial, se realza el valor de la propia persona del educador - decía Marcos: «En materia educativa interesa más lo que el maestro es que lo que el maestro sabe y conoce»-, por lo que se plantea la necesidad de que su formación y capacitación atienda, esencialmente, al conocimiento de sí mismo y a su propio desarrollo personal como herramientas fundamentales.

Esta selección de conferencias apunta a generar una reflexión sobre la importancia de que el educador sea capaz de profundizar en sus propios afectos, pulsiones, componentes infantiles, aspectos personales irresueltos, entre otros elementos, y tenga el valor de reconocerse a sí mismo y reconocer el rol primordial que juegan la singularidad y la complejidad de su persona en su quehacer como educador. De esta manera, será capaz de entender el mundo psíquico de sus estudiantes y el valor de la subjetividad en las relaciones humanas, con lo cual podrá manejar de forma más saludable su posición de poder como adulto y orientar a sus alumnos en su crecimiento y desarrollo emocional con un mayor margen de garantía de salud y equilibrio.

Se trata de una obra que invita a los educadores a que piensen en la posibilidad de desarrollar una función analítica que les permita aprovechar las múltiples vicisitudes y dificultades que surgen en su relación con los alumnos y que no están en el programa educativo oficial - esas frente a las cuales su propio mundo inconsciente responderá lo quieran o no-, y las puedan integrar en el proceso de aprendizaje, en busca del crecimiento psicológico de los alumnos. En otras palabras, es una invitación a que los educadores se atrevan, formándose desde una perspectiva psicoanalítica, a aventurarse en el mundo del inconsciente y a vencer el miedo a la incertidumbre para abrir la posibilidad de aprendizaje y transformación. 
Se trata de una ruta para ingresar a los procesos mentales subyacentes, especialmente cuando la enseñanza y el aprendizaje se ven «interferidos» por diversos impulsos y comportamientos que, generalmente, no queremos ver ni atender pues no los consideramos parte de «la clase programada», pero que son parte esencial del proceso educativo.

Esta publicación rescata, además, la relevancia del vínculo educativo -y sus semejanzas con el vínculo madre-hijo- en el proceso de aprendizaje $y$, por ende, la importancia de la labor tutorial de los maestros al interior de las escuelas. Nos hace pensar en cómo, si bien el aprendizaje puede ser doloroso y frustrante, también puede ser placentero y satisfactorio, por lo que es indispensable que todo educador aprenda a escuchar los contenidos manifiestos y encubiertos que emergen de sus alumnos y de sí mismo; a contener y acoger a otros que están en proceso de maduración y formación; y a ser capaz de gozar y tolerar frustraciones para, así, sembrar en los estudiantes el deseo de vivir, de aprender y de transformar sus corazones.

Esta obra nos recuerda que la relación educativa es un vínculo afectivo, de amor, con un contenido ético, pues supone, ante todo, un acto de reconocimiento. Y nos permite evocar dos aspectos esenciales en la tarea educativa pero que a menudo olvidamos por priorizar cuestiones técnicas y cuantitativas: la importancia del respeto e interés por los estudiantes, por su propia historia, su mundo interno, sus necesidades y expectativas; y la necesidad de reconocerlos y atenderlos como seres únicos y singulares, con voz propia, y no como un conjunto de apellidos y números, como una masa anónima y uniforme que hay que amoldar según diversos perfiles y exigencias sociales, o como un grupo de clientes a los cuales hay que atender obedeciendo a un acto contractual.

Como ocurre con la mayoría de textos pensados para ser conferencias, los escritos de Marcos fueron elaborados para ser leídos en voz alta por él mismo, de manera presencial y efímera; o, en algunos casos, para ser una 
guía a partir de la cual estructurar un discurso ordenado y claro, dirigido a una población en especial. Muchos de ellos incorporaban anotaciones y preguntas personales, ideas incompletas, referencias inconclusas, datos por precisar y diversos cabos sueltos, pues no fueron creados para una publicación. En este sentido, el trabajo de compilación y edición de este libro ha consistido en revisar y afinar el contenido y la forma de cada una de las catorce conferencias, respetándolas al máximo pero dándoles un tratamiento más formal en cuanto a su redacción.

Para efectos de la edición, se han agregado, a pie de página, algunas aclaraciones conceptuales sobre ciertos términos psicoanalíticos que el propio autor consideraba necesarias. Asimismo, se ha completado una serie de datos sobre cada una de las conferencias (año, lugar, contexto, etcétera) ${ }^{3}$, sobre la bibliografía consultada por el autor en estas y sobre algunas otras referencias que hemos considerado pertinentes para su adecuada contextualización y comprensión. Cabe añadir que todas las notas a pie de página corresponden a estas aclaraciones bibliográficas o conceptuales del trabajo de edición, menos aquellas en las que se indica explícitamente que son notas del autor.

¿Cómo no hacer realidad este sueño? ¿Cómo no compartir el tesoro que habita en estas conferencias? Tener a cargo la edición de esta obra ha sido un gran honor y también una gran responsabilidad, pues es un compromiso con la difusión del pensamiento y del modelo de trabajo de Marcos en nuestro país y en el resto del mundo. Pero, además, esta labor ha significado un verdadero placer porque ha sido como volver a dialogar con él, intensamente, como solíamos hacerlo. He escuchado su voz y su risa, mentalmente, una y otra

3 Si bien logramos precisar los años en los que se desarrollaron todas las conferencias, así como la ciudad donde se realizaron, lamentablemente hubo algunos casos en los que, por falta de datos, no conseguimos precisar el evento particular en el que se dieron o la institución que invitó al autor a presentarlas. 
vez, mientras iba repasando cada uno de sus escritos y venían a mí gratos recuerdos y complicidades en una catarata de imágenes.

Marcos fue un hombre con un sinfín de anécdotas; le encantaba evocar historias, relatos, metáforas, refranes y dichos. Una de sus frases favoritas y que recordaba con frecuencia era la siguiente: «Lo que natura no da Salamanca no presta». Sin lugar a dudas, a Marcos la naturaleza le dio innumerables dones que supo aprovechar y compartir con gran amor y auténtica vocación. Ahora que lo extrañamos, honremos su recuerdo disfrutando del tesoro que nos dejó a través de su voz y su palabra. 


\section{El sembrador}

Si me pidieran que defina a Marcos con dos palabras, estas serían «pasión» e «intensidad». Su primera gran pasión fue Fanie, el amor de su vida. La intensidad que puso en su relación con ella fue un elemento fundamental para conformar una vida matrimonial rica en experiencias y devociones, con alegrías y tristezas compartidas que nutrieron a una familia capacitándola para enfrentar la vida con igual pasión.

Su segunda gran pasión fue la música. No le bastó con ser un gran conocedor de música y un melómano excepcional. Su intensidad lo llevó a arrancarle los secretos al violín, a establecer una relación estrecha con el piano y a dirigir un coro.

Su tercera gran pasión fue la psiquiatría. La intensidad con que buscó entenderse y entender los ignotos caminos por los que discurre la mente humana lo condujo a lo más profundo del psicoanálisis, disciplina a la que hizo importantes aportes que, estoy seguro, algún día serán debidamente reconocidos por sus colegas en el Perú, como ya lo han sido en Argentina y Brasil.

Su cuarta gran pasión fue la educación, a la cual llegó gracias a su intensa convicción de que el psicoanálisis podría ser un instrumento valioso para transformar el clima social dentro del aula, mejorando las relaciones entre los alumnos, y la que se establece entre estos y sus profesores. La intensidad que 
puso en su trabajo en el aula y con grupos de docentes lo guió por desarrollos imaginativos que abrieron nuevas rutas de investigación y trabajo para el psicoanálisis. No dudo de que sus colegas irán reconociendo estos aportes como contribuciones pioneras a medida que sus planteamientos, escritos y metodologías vayan calando entre los estudiosos del tema, de la misma forma que marcaron profundas huellas en los maestros que accedieron a sus cursos y talleres en el Centro de Desarrollo Humano y Creatividad, que formó para desarrollar y difundir sus teorías y experiencias.

$\mathrm{Su}$ quinta gran pasión fueron las plantas. Las estudió, coleccionó, cuidó, reprodujo y amó con una intensidad que se refleja en el jardín que construyó con paciencia y sapiencia, y que es motivo de admiración. Nunca pude entender de dónde sacaba las veinticuatro horas adicionales que le permitían ir de hoja en hoja, de planta en planta, cuidándolas y recordando sus nombres y sus orígenes.

Además, como si para él el tiempo fuera un globo que se expandía para acomodar toda su vitalidad, era un gran lector y un conversador capaz de discutir por largas horas sobre cualquier tema que lo apasionara. Podía decir con Terencio: «Hombre soy y nada de lo humano me es ajeno». Y como si todo esto fuera poco, hizo un culto de la amistad, siempre pronto a dar consejo, compañía, apoyo y presencia al amigo.

Marcos vivía en un movimiento perpetuo que desafiaba las leyes de la vida y que, por una complicada asociación de ideas, me traía a la memoria — si bien en un contexto y connotación diferentes- uno de los diálogos que Umberto Eco pone en boca de los dos personajes principales de su novela El nombre de la rosa. Me refiero a aquel pasaje en el que Jorge Burgos le pregunta a Guillermo de Baskerville: «¿Qué te preocupa de mi celo?», y este le contesta: «Tu prisa».

Y si nos dio una lección de vida, también nos brindó una lección de muerte. Muchos fantaseamos con la idea de una muerte súbita, sorpresiva, como la mejor salida de este mundo. Él supo, con certeza y en detalle, dada su condición de médico, que la suya iba a ser no solo una muerte anunciada, sino 
también predecible en todas sus etapas. Y lo que para muchos hubiera sido motivo suficiente para echarse a esperar el desenlace, para él fue un acicate para agregarle otras veinticuatro horas a sus días y entrar en una vorágine de viajes, proyectos, reuniones, convocatorias y todo tipo de actividades que acrecentaron su presencia en la memoria colectiva de quienes lo admirábamos y queríamos.

Amante (más que esposo), padre, abuelo, amigo, músico, médico, consejero, educador, innovador, botánico y mucho más. ¿Cómo podían tantas cosas caber en una sola cabeza? Necesitamos otro Marcos para que nos aclare este enigma.

Creo que todo lo anterior podría resumirse en una frase brillante de él mismo - como fueron todas las suyas- y que nuestro amigo común Ed Schonberg recordó cuando le pedí que me hiciera un comentario sobre Marcos: «Siempre me dio la impresión de que vivía a una temperatura más alta que el común de los mortales: sus entusiasmos eran simplemente más intensos. Una frase que utilizaba muy a menudo decía: “¡No te puedes imaginar!". Era como si él mismo se sorprendiese frente a la intensidad de sus propias vivencias».

Isaías Flit

Isaías Flit estudió Ingeniería Mecánica. Su actividad laboral ha estado relacionada con proyectos, asesorías y trabajos en empresas e instituciones nacionales e internacionales; con el desarrollo y financiamiento de proyectos científicos y tecnológicos; y con la propiedad intelectual. Ha participado en la enseñanza y difusión de temas vinculados con sus actividades. Su larga y muy cercana relación con Marcos Gheiler surgió de intereses comunes por la literatura y el arte, y sobre todo del diálogo alimentado por la permanente curiosidad en torno a todo lo humano. 
Para poder revisar todo el contenido de esta edición, visite nuestra tienda virtual.

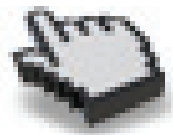

Gobierno electrónico

Análisis de los conopptos de tenologia, comodidad y democracia

Joaquin Yrivarren Espinoza

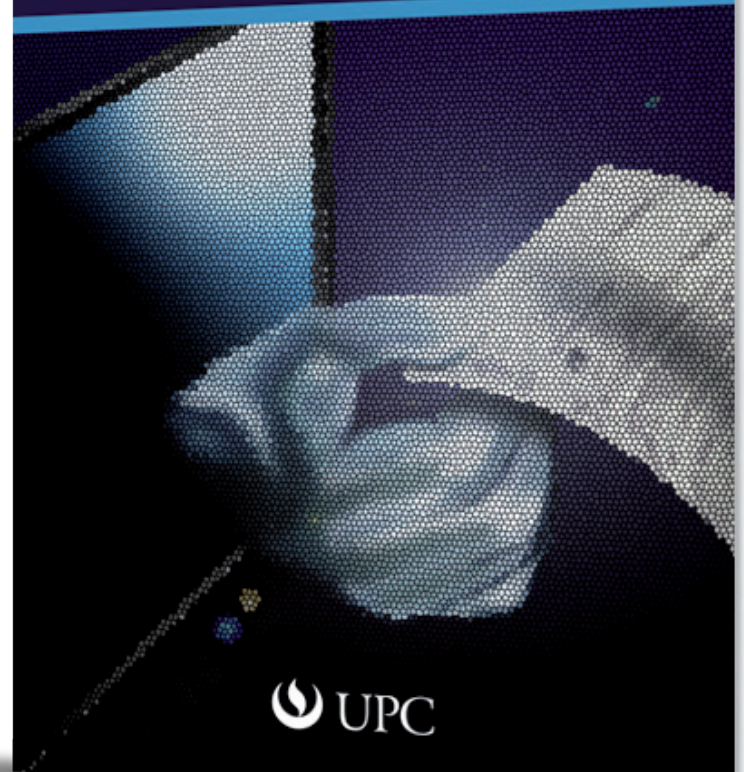

